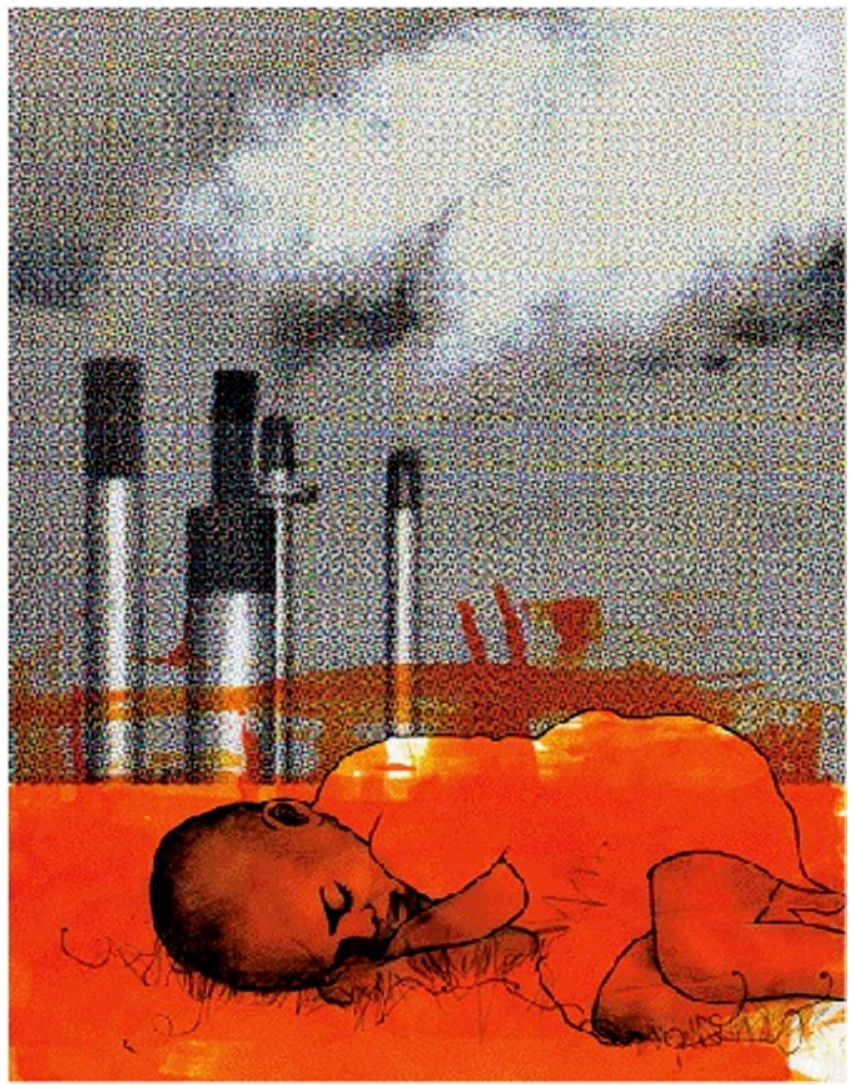

João Paulo Tiago

\title{
Super Mario Clouds and the John Ford Sky: Love and Loss in the Work of Douglas Gordon and Cory Arcangel
}

\section{Robert Burgoyne}

R.Burgoyne@wayne.edu

Robert Burgoyne is a Professor of Film and Media studies at Wayne State University in Detroit. His most recent book publication is the Hollywood Historical Film. (1) His previous book, Film Nation, has been translated into Portuguese and published as A Nação do Filme. (2)

\section{Abstract:}

A shared culture of art practice has emerged around classical Hollywood films and interactive video games, an art practice that uses both of these dominant media as a type of "readymade." One critic has called contemporary video artists 
such as Cory Arcangel and Douglas Gordon the "ideal children of the children of Duchamp." Reformulating well known films, video games, and television broadcasts, these artists provide a way of customizing industrially produced pleasures, reconfiguring in a personal and illuminating way the objects of audio-visual culture.

Keywords: Douglas Gordon, Cory Arcangel, Marcel Duchamp, The Searchers, Psycho, The Exorcist, The Beatles

Christian Metz writes that cinephilia represents, in part, the impulse to preserve and protect the good object, to save it from obliteration - not the film itself, the celluloid, nor the institution, but rather the social memory embodied in the cinema-object. Two recent installations, "The Five Year DriveBy" by Douglas Gordon and "Super Mario Clouds" by Cory Arcangel, would seem to make this point explicitly. In both, the impulse to save and protect is linked to the artists' childhoods, and duplicated in the texts that provide the artists with their source material: The Searchers by John Ford and the video game, Super Mario Brothers, both of which have plots that revolve around rescue. The two installations can be read as a way of maintaining these objects in what Metz calls an "imaginary enclosure of pure love".(3)

"The Five Year Drive-By," a five year long projection of The Searchers on a drive-in size movie screen installed, among other places, in the California desert, draws from the artist's memory of the powerful effect of the film when he first saw it as a boy. By slowing it down to the point that each frame is held for 45 minutes, it becomes a kind of Deleuzian time-image, a work that is centrally concerned with duration, the passing and arresting of time and self, the near capture of a moment that is "frozen in time." It also suggests the disappearing social memory of the Western, a genre that has almost entirely been erased from cultural memory. The installation in effect amplifies the theme and the plot of the film, which is centered on loss, memory, and the "saving" of the past.

Cory Arcangel's "Super Mario Clouds" seems to draw from a different cultural encyclopedia, but the sense of affect surrounding the work is similar. Isolating the moving cloudscape that serves as background to the early videogamesuper Mario Brothers, the artist eliminates the buildings, barriers, and the figure of Mario himself to concentrate simply on the clouds drifting by in a serene blue sky. Projected on a large screen in a museum space, the 
installation suggests the earliest moments of video game culture, the primal scene of an emergent technology linked to the generational memory of the artist. Stripped of the linear forward momentum of the game, the screen becomes an image of transience, of fleeting impermanence, a loop centered on memory, duration, and loss. Like The Searchers, the goal of the game Super Mario Brothers is the rescue of a female "character," in this case, the Princess Toadstool, who can be saved only after transiting a game space filled with hazards. By erasing the quest aspect of the game to concentrate on a fragment of mise-en-scène, the artist elicits an emotional connection to the past, to childhood, and to early game culture.

In this essay I explore the work of Gordon and Arcangel as a way of rethinking issues circulating around the concept of cinephilia and pleasure. Although the gap between classical cinema and video games has been much emphasized in contemporary theory, a shared culture of art practice has emerged around these two dominant forms, a practice that uses the media as a type of "readymade." One critic has called contemporary video artists such as Arcangel and Gordon the "ideal children of the children of Duchamp." Reformulating well known films, video games, and television broadcasts, these artists provide a way of customizing industrially produced pleasures, reconfiguring in a personal and illuminating way the objects of audio-visual culture.

Arcangel has worked in a variety of media, but his most evocative objects are the repurposed video games, which include a Japanese racing game, stripped of all but the endlessly scrolling road, moving hypnotically from the horizon toward the viewer in an unending loop, an installation he calls "F-1 Racer," and a new computer program that he wrote for Super Mario Brothers called "Mario Movie," in which Mario floats through obstacles, encounters antagonists drawn from Pac-Man, falls endlessly through video space racing by game objects and game architecture, and winds up alone on a cloud, crying .

Gordon's work, similarly, centers on cinematic readymades, including, in addition to the "Five Year Drive By," the early "24 Hour Psycho," a slowing down of the Hitchcock film to a 24 hour running time, and "Between Darkness and Light (After William Blake)" in which two films are projected onto the back and the front of a semi-transparent cinema screen so that the images bleed through and are lightly superimposed. The two films, The Exorcist and The Song of Bernadette, are both films about possession. They are non-synchronized, and thus appear differently, with different combinations of images every time they are viewed. The images of Regan's demonic head 
superimposed on the images of a praying Bernadette, or of Bernadette's 19th century peasant mother walking out of Regan's suburban mansion are typical of the combinations created. As J. Hoberman writes, "However much The Song of Bernadette and The Exorcist may crash each other's parties, they emerge as essentially the same movie - lit by candles, filled with crosses, endlessly talking about God and faith. Bernadette will never exorciseThe Exorcist, but united as between darkness and light, they constitute a pageant."

Metz devotes a few, powerfully evocative paragraphs to cinephilia in The Imaginary Signifier. Comparing the cinephilia of the film historian and the archivist, the cinephilia of the ardent champion of certain auteurs, and the cinephilia of the theorist, Metz makes the striking point that all cinephilia comes at a cost: the mystery and fascination of the cinema, in every case, is converted to something else. Depending on the particular form it takes, it can become a kind of fetishism, as in the obsessive drive of the collector or the extreme connoisseur; or it can become a kind of sadistic voyeurism, seen in the discourse of the "expert" or the theorist who desires nothing more than to "take the film apart." As Metz writes, "To study the cinema: what an odd formula! How can it be done without 'breaking' its beneficial image ... by breaking the toy one loses it".(4)

In many ways the art installations of Douglas Gordon and Cory Arcangel can be seen precisely as "breaking the toy." In Gordon's work, The Searchers is slowed down so that the illusion of human movement is reconstituted as a series of frozen images. The fundamental illusion of the cinema, the illusion of motion, gives way to an image that reads like sculpture. The nearly static images Gordon creates also highlight the basis of film in still photography - a reversal of early film projections that often began with still images, held for awhile to increase suspense, until they would suddenly spring into life-like movement. Writing about the astonishment that attended the first film screenings, Tom Gunning argues that the audiences' sense of surprise and pleasure was enhanced by the dramatic, trompe-l'oeil presentation with which the films were introduced, a presentation that emphasized the moment of transformation from still to moving pictures. Rather than a naïve belief in the realism of the moving image, the amazement that greeted the first moving image projections was more an appreciation of the feat of creating life-like movement in a photographic medium. The "birth" of cinema in 1895 was understood, he argues, as a style of theater comparable to prestidigitation, magic theater, and illusionism. And in Gunning's view, the key to the dramatic impression created by the first projected films 
was the showman-like heightening of the passage from static image to moving pictures. (5)

Expanding on this historical insight, we can begin to think of the static image, the frozen tableau, as an integral part of the aesthetic of cinema, an element that was utilized in the first cinematic projections by the brothers Lumiere and remains as the undertone or undercurrent of every experience of film. Usually a concealed part of the code of the moving image, the static image might be seen as an aesthetic potential, an always available aesthetic resource. In Gordon's work we have a reverse evolution, a recoding of the fundamental illusion of the cinema, returning us by an unforeseen path to the earliest days of cinematic projection, and reminding us of an element or experience that was emphasized in the earliest film projections - "breaking the toy" in order to rethink the basic illusion of stillness and motion.

This idea has been explored from time to time by critics as diverse as Moholy-Nagy and Laura Mulvey, but only in a fragmentary way. Mulvey writes of the advent of dvds, and the ability to stop, rewind, and freeze-frame at will, that "this new, freely accessible stillness, extracted from the moving image, is a product of the paradoxical relation between celluloid and new technology. It is primarily the historic cinema of celluloid that can blossom into new significance and beauty when its original stillness ... is revealed in this way. The cinema has always been a medium of revelation".(6) In Gordon the repurposing of existing film and media artifacts evokes an alternative aesthetic, present in embryo at the beginnings of the art form, an underground current of aesthetic design that moves to the surface from time to time within the mainstream traditions of film.

At first glance, the work of Cory Arcangel would appear to be driven by very different questions, and to refer to a very different cultural encyclopedia. However, the game art of Arcangel, like the video and film art of Gordon, also involves "breaking of the toy," in this case, literally "breaking" old video games. Arcangel's game art involves opening the game cartridge in old Nintendo or Atari games, removing the chip installed in them to delete some of the gaming code and then re-formulating the work, soldering the pieces back together, in order to produce contemplative, and very different moving image installations. The hypnotic movement of the endlessly scrolling road in "F-1 Racer" and the oneiric horizontal drift of the two-dimensional clouds in "Super Mario Clouds" offer a kind of precise analogue, expressed in the medium of game art, to Metz's comments: "I have loved the cinema, I no longer love it. I still love it". (7) 
As part of the installation of "Super Mario Clouds" and "Mario Movie," Arcangel provides detailed instructions on the technique of deleting code from the Nintendo chip, how to reprogram it, and how to resolder the new program back into the game console, demystifying the video game in order to reillusion it. Arcangel also describes the complete digital formula for constructing both the original game as well as his own game art. The computer games Arcangel treats appeared early in the history of the medium, and are thus relatively simple to program and to understand, which allows for a kind of primitive artistic appropriation and manipulation. Here, the hand of the artist returns in a medium that had been defined by digital code. Seemingly as far removed from the hand of the artist as they could possibly be, digital video games, in the work of Arcangel and other game artists, can now be linked with the return of craft based art forms such as hand made books, YouTube videos, sculptures made from repurposed materials, and audio remixes.

Arcangel's media hacks and rewrites are extraordinarily various. One of his recent installations stages a kind of assault by computer program on the artifacts of mainstream pop culture - more specifically, the cultural memory embedded in mainstream popular culture. For example, in the installation he calls "Untitled (After Lucier)," he rebroadcasts in a continuous repeating loop the Beatles televised performance on the Ed Sullivan show in 1964, perhaps the most iconic moment in the history of the television medium. Over time, the video performance slowly decomposes; during the first week or so of its run, the historic video looks normal. As time wears on, however, the pixels shift shape, enlarging into blocks, distorting and making the four Beatles, their guitars, and their signature haircuts almost unrecognizable. They become, as one writer says, "increasingly indistinct and further from memory ... an artifact of digital compression and cultural disintegration".(8) As Arcangel says, "The longer it goes on, the better the piece looks, and the less embarrassing it is."

The pace of spectacle and media culture, dominated by speed, novelty, and distraction, is replaced here by a contemplative work that unfolds over the course of weeks and months. In early modernism, as David Campany writes, the "photo-eye and the kino-eye (film-eye) were the driving metaphors for a new and dynamic intimacy between 'man' and optical machine". (9) The optical machines of contemporary video game culture, however, go well beyond this, incorporating an accelerated motor component, a heightened interactive merging of the tactile and the optical. For his part, Arcangel works in the opposite direction of the adrenalized thumb culture that has developed around video games: "I like to take the interactivity out of things actually".(10) Working against the 
dominant current, he discovers a quality of slowness in video games and in the experience of the Beatles television performance, a quality of slowness that reads as resistance to speed, a slowness that responds to the kineticism of media culture with hypnotic and repetitive loop sequences that impose a slow pace upon the viewer.

It is easy to appreciate the playful, innovative uses that Arcangel makes of mass media, the sense of reverie they induce, and his seemingly sunny perspective on mass media culture as a playground for inspired invention. His is a perspective comparable to Roland Barthes' way of characterizing his experience in the souk in Tangiers, where the myriad voices and languages of a bar in the North African square drifted around and through him: "music, conversations, the noises of chairs, of glasses, an entire stereophony of which a marketplace in Tangiers ... is the exemplary site ... I myself was a public place, a souk; the words passed through me, small syntagms, ends of formulae, and no sentence formed".(11) But within the artist's exploration of the pleasure of the fragment, the bits of game code, and the isolated segment, a certain elusive but powerful point about media culture can be discerned.

Victor Burgin describes contemporary visual culture as a "cinematic heterotopia," a network of overlapping but distinct cinematic interfaces and experiences. Drawing from Michel Foucault's description of heterotopia -- a space where several sites that are incompatible in themselves are juxtaposed Burgin focuses on the cross currents of the mediascape, and the way they converge in the typical, daily experience of the ordinary person. One of the consequences of this cinematic heterotopia, as Burgin describes it, is that films are now often viewed in fragments, rather than from start to finish. And they are viewed with varying degrees of attentiveness, ranging from indifferent observation to active engagement. The spectrum of media forms universally available in contemporary culture, that cross into the spectator's lives whether they seek out the film or not, makes the ordinary spectator into an unwitting mimic of one of the great avant-garde experiments of the early 20th century, what the Surrealists Andre Breton and Jacques Vache called the "derive," the practice of dashing from one cinema to another in order to achieve the disorientation that the Surrealists believed could open onto a critique of everyday life. This once radical practice of disorientation has, in effect, become a mainstream activity, a powerful way to customize pleasure. In its passage to the everyday, the fragmentation and decomposition of film has, as Viktor Shklovsky says, "completed its journey from poetry to prose". (12) 
As audio visual forms continue to proliferate, with an increasing range and number of screens, or interfaces, defining the practices of everyday life, the work of artists at the edge of culturally dominant media becomes more important. The relevance of these works to contemporary screen culture is directly related to the pleasure they elicit. I began by discussing cinephilia as a protective, deeply personal preoccupation, one that sought to rescue and preserve the "good objects" of the past from oblivion. However, the cinephilic gesture of drawing these works into an "imaginary enclosure of pure love," as Metz describes it, seems to fall short of the discursive and imaginative resonance of the art I describe above. Gordon and Arcangel employ readymade objects of media culture in ways that have little to do with the past, and everything to do with experiences of the present moment, a moment aptly characterized by Burgin as a "cinematic heterotopia."

The pleasure and interest of these projects involve a reversal of the kineticism, the speed, and the almost tactile stimulation that Benjamin, among others, saw as cinema's vocation and the emblem of its modernity. Here, the fascination comes from slowness, from the stilled image, from absorption in a simplified set of looped images, from contemplation rather than distraction. And what also comes powerfully into view in these works, in another reversal, is a surprising sense of the return of the aura. What Benjamin predicted would wither away in the age of mechanical, and now electronic, reproduction returns with new force in the frozen images from The Searchers and Psycho, and in the disintegrating images of the Beatles. Ethan Edwards, Marion Crane, the Beatles, are rendered, finally, as the auratic figures they always were. Nor does the power of these forms derive solely from the original works, a kind of borrowed or "acquired aura."(13) Rather, it seems that the hybrid relation between film and electronic media opens up new areas of fascination, and new possibilities for seeing into the culture's images.

\section{Notas}

[1]Wiley-Blackwell, 2008.

[2] Brasilia, 2003.

[3]Christian Metz, "The Imaginary Signifier," trans. Celia Britton, Annwyl Williams, Ben Brewster and Alfred Guzzetti (Bloomington: Indiana University Press, 1982), 13 .

[4] Metz, 80 .

[5]Tom Gunning, "An Aesthetic of Astonishment: Early Film and the

(In)Credulous Spectator," in Linda Williams, ed., Viewing Positions: Ways of Seeing Film (Rutgers University Press, 1995) 114-133.

[6] Laura Mulvey, "Stillness in the Moving Image," in David Campany, ed., The Cinematic co-published by Whitechapel and The MIT Press, 2007) 139. [7] Metz, 79. 
Txt: Leituras Transdisciplinares de Telas e Textos, Belo Horizonte, v.4, n.7, p.36-44, 2008

[8] Carly Berwick,

ww.samsung.com/Features/Brand/magazinedigitall/2006 winter/feat.

David Campany, "Introduction//When to be Fast? When to be Slow?" in

Campany, ed. The Cinematic (London: Whitechapel, co-published with

Cambridge: The MIT Press, 2007), 10.

[10]Berwick, 2 .

[11]Roland Barthes, The pleasure of the text, 67.

[12] See Burgin, 198.

[13] This phrase comes from Douglas Crimp, quoted in Pater Lunenfeld, Snap

to Grid (Cambridge: The MIT Press, 2000), 63. 